\title{
Analysis of Individual Variations in Autonomic Responses to Urban and Forest Environments
}

\author{
Hiromitsu Kobayashi, ${ }^{1}$ Chorong Song, ${ }^{2}$ Harumi Ikei, ${ }^{2,3}$ \\ Takahide Kagawa, ${ }^{3}$ and Yoshifumi Miyazaki ${ }^{2}$ \\ ${ }^{1}$ Ishikawa Prefectural Nursing University, 1-1 Gakuendai, Kahoku, Ishikawa 929-1210, Japan \\ ${ }^{2}$ Center for Environment, Health and Field Sciences, Chiba University, 6-2-1 Kashiwa-no-ha, Kashiwa-shi, Chiba 277-0882, Japan \\ ${ }^{3}$ Forestry and Forest Products Research Institute, 1 Matsunosato, Tsukuba, Ibaraki 305-8687, Japan \\ Correspondence should be addressed to Yoshifumi Miyazaki; ymiyazaki@faculty.chiba-u.jp
}

Received 29 July 2015; Accepted 20 September 2015

Academic Editor: Giuseppe Caminiti

Copyright (C) 2015 Hiromitsu Kobayashi et al. This is an open access article distributed under the Creative Commons Attribution License, which permits unrestricted use, distribution, and reproduction in any medium, provided the original work is properly cited.

\begin{abstract}
Autonomic responses to urban and forest environments were studied in 625 young male subjects. The experimental sites were 57 forests and 57 urban areas across Japan. The subjects viewed the landscape (forest or urban environment) for a period of 15 min while sitting on a chair. During this period, heart rate variability (HRV) was monitored continuously. The results were presented as histograms and analyzed with special reference to individual variations. Approximately $80 \%$ of the subjects showed an increase in the parasympathetic indicator of HRV (lnHF), whereas the remaining subjects showed a decrease in the parasympathetic activity. Similarly, $64.0 \%$ of the subjects exhibited decreases in the sympathetic indicator of HRV $(\ln [\mathrm{LF} / \mathrm{HF}])$, whereas the remaining subjects showed opposite responses. Analysis of the distribution of HRV indices (lnHF and $\ln [\mathrm{LF} / \mathrm{HF}]$ ) demonstrated the effect of forest environments on autonomic activity more specifically than the conventional analysis based on the difference in mean values.
\end{abstract}

\section{Introduction}

Recently, there has been growing interest in the effects of the natural environment on human health. Beneficial effects may include stress relief, improved cognition and physical activity, better social cohesion, and promotion of overall health and mental well-being [1]. The predisposition of humans to responding positively to the natural environment may be a result of past adaptation to natural environments for survival or ongoing well-being during evolution [2].

The psychological effects of exposure to a forest environment on emotions have been demonstrated by various researchers. Bowler et al. [3] performed a meta-analysis of the results of several studies on the effect of natural environments and concluded that the natural environment has a consistent effect of reducing negative emotions (anger, fatigue, or sadness). In addition, exposure to a forest environment may have a positive effect on psychiatric impairments, such as alcoholic depression [4].
In recent years, along with psychological responses, physiological responses to a forest environment have been investigated. Studies have demonstrated that exposure to a forest environment results in reduced physiological indicators for stress. For example, lower fluctuation in skin conductance, shorter pulse-transit time (suggesting lower blood pressure), lower tension in frontalis muscles, and lower heart rate were observed during exposure to a video of natural settings [2]. Exposure to real forest environments decreased salivary cortisol concentration $[5,6]$ and cerebral blood flow (indicating a relaxation in brain activity) [6] and increased natural killer (NK) cells (indicating an enhancement of the immune system) [7-9]. Furthermore, Ohtsuka et al. [10] reported that a long-term experience in forest environment has significantly reduced blood glucose levels in patients with diabetes.

The current study investigated the effects of forest environments on autonomic nervous activity using heart rate variability (HRV) as an indicator. The relationship between 
HRV and autonomic functions has been established by previous studies [11-13]. Use of HRV as a physiological indicator of stress is also well established. In addition, during recent years within the field of alternative medicine, the effect of acupuncture has been evaluated by HRV $[14,15]$.

Our previous studies have demonstrated an increase in the high frequency (HF) component and/or a decrease in the low frequency (LF)/HF ratio of HRV in forest environments [16-19]. Similar results have been observed in parks in urban areas $[20,21]$ or during exposure to indoor plants $[22,23]$. The HF component of HRV is considered a marker of parasympathetic activity, whereas the LF component or LF/HF ratio is considered a marker of sympathetic activity [24]. Thus, the results of the abovementioned studies suggested a relative activation of the parasympathetic function.

Use of HRV for evaluating stress provides some advantages over alternative physiological measurements. HRV can be recorded continuously in a noninvasive manner. Furthermore, use of a portable heart rate monitor can provide ambulatory recording of HRV. These advantages might be maximized in field studies rather than experimental studies. Thus, HRV can be the appropriate indicator of physiological responses to forest environments.

One of the features of the current study is an analysis with special reference to the distribution characteristics of individual variations in the HRV response. Most previous studies on physiological responses to environments have focused on the differences in the mean value; individual variations were considered an error or impurities. Individual variations have been an underutilized resource in various fields of life sciences. Bennett [25] described the tendency of focusing on means as the "tyranny of the golden mean." From the viewpoint of adaptation, individual variations should have biological and/or evolutionary significance and should decidedly not be viewed as an error or impurity. The mean value has certain significance as one of the representative values of a population; however, it represents no more significance than any other aspect of the physiological responses of a population.

Analysis of the physiological response focusing on individual variations may be challenging compared with an analysis focusing on the mean value because the analysis of individual variations requires a larger sample size. The current study investigated the frequency components of HRV in 625 young Japanese males in urban and forest environments. The current study utilized a large sample size and can therefore provide a new perspective on the physiological responses to natural environments.

\section{Materials and Methods}

2.1. Study Sites and Subjects. The study sites were 57 forest and 57 urban areas across Japan. The chosen urban sites were downtown or nearby a Japan Railway (JR) station.

Although 684 young Japanese male university students participated in the experiments, only 625 subjects with complete data for both urban and forest sites were included in the analysis. The demographic parameters of the subjects are shown in Table 1.
TABLE 1: Demographic parameters of the subjects $(n=625)$.

\begin{tabular}{lccc}
\hline & Age (years) & Height $(\mathrm{cm})$ & Weight $(\mathrm{kg})$ \\
\hline Mean & 21.6 & 172.3 & 64.7 \\
SD & 1.6 & 5.6 & 9.6 \\
Max & 29 & 188 & 110 \\
Min & 19 & 155 & 42 \\
\hline
\end{tabular}

*SD: standard deviation.

None of the subjects reported a history of physical or psychiatric disorders. Consumption of alcohol and tobacco was prohibited and consumption of caffeine was controlled during the study period. The study was performed according to the regulations of the Ethics Committee of the Center for Environment, Health, and Field Sciences, Chiba University, or the Institutional Ethics Committee of the Forestry and Forest Products Research Institute in Japan.

2.2. Physiological Measurements. HRV was measured using a portable electrocardiograph (Activtracer AC-301A, GMS, Japan). Spectral analysis of HRV was conducted for 15 min recordings using HRV software (MemCalc/Win, GMS, Tokyo, Japan) based on the maximum entropy method. The $\mathrm{HF}$ and LF components were obtained by integration of the power spectra at the respective ranges of $0.15-0.40$ and $0.04-0.15 \mathrm{~Hz}$. The natural logarithms of the HRV indices (lnHF, $\ln [\mathrm{LF} / \mathrm{HF}]$ ) were then calculated, considering that the raw HRV components indicate skewed distributions [26]. In the current study, HRV was measured during spontaneous breathing, and paced breathing was not applied. The subjects were instructed to avoid irregular breathing during the measurements. A previous study has reported that paced breathing has a negligible effect on interindividual variations in the spectral components of HRV [27].

2.3. Experimental Design. The experiment was performed at each experimental site over 2 consecutive days. Before the experiment, the aim of the study and the experimental protocol was explained and general instructions were provided to the subjects. The subjects ate lunch between 11:30 and 12:30, and the measurements were conducted between 13:30 and 15:30. All subjects were nonsmokers. Alcohol intake and unusual physical activity on the day before the measurement were forbidden.

The subjects at each site were randomly divided into two groups, and the order of exposure to the experimental conditions (urban or forest) differed among the two groups. One group was exposed to the forest site prior to the urban site, and the other group followed the reverse order. All subjects remained in a waiting room before moving to the field site. All subjects were instructed to rest on a chair for $5 \mathrm{~min}$, which mitigated the physiological effects of any possible physical activity before the measurement period. HRV measurements were obtained during $15 \mathrm{~min}$ when the subjects viewed the landscape. On the second day, the subjects switched the field sites. The experimental protocol on the second day was the same as that on the first day. 
TABLE 2: Descriptive statistics of the distribution of heart rate variability $(n=625)$.

\begin{tabular}{|c|c|c|c|c|c|c|}
\hline & \multicolumn{3}{|c|}{$\ln \mathrm{HF}$} & \multicolumn{3}{|c|}{$\ln (\mathrm{LF} / \mathrm{HF})$} \\
\hline & Urban & Forest & Urban-forest & Urban & Forest & Urban-forest \\
\hline Mean & 5.54 & 6.02 & -0.48 & 1.48 & 1.32 & 0.16 \\
\hline Median & 5.66 & 6.14 & -0.45 & 1.51 & 1.31 & 0.16 \\
\hline $\mathrm{SD}$ & 0.92 & 1.01 & 0.70 & 0.77 & 0.82 & 0.71 \\
\hline 5th percentile & 3.81 & 4.41 & -1.57 & 0.16 & 0.00 & -0.92 \\
\hline 95th percentile & 6.9 & 7.29 & 0.56 & 2.70 & 2.66 & 1.19 \\
\hline Skewness & -1.20 & -1.10 & -0.92 & -0.21 & 0.32 & -0.46 \\
\hline Kurtosis & 3.42 & 2.97 & 8.21 & 0.47 & 0.97 & 4.24 \\
\hline
\end{tabular}

*SD: standard deviation; skewness: a measure of symmetry of distribution; Kurtosis: a measure of whether the distribution curve is peaked (positive) or flat (negative) relative to the normal distribution.

Among the experiments at 57 sites, the experimental design used at 44 sites was the "Stay-in Forest Therapy" design, where arrangements were made for all subjects to reside in a hotel with identical single rooms. At the remaining 13 sites, the experimental design of "One-Day Forest Therapy" was used, where the subjects were allowed to return home after the first day. To reduce inconvenience to subjects and to limit research expenses, we switched to the simplified experimental design of One-Day Forest Therapy.

2.4. Data Analysis. Mean, median, standard deviation (SD), 5 th and 95th percentile values, skewness, and kurtosis were calculated for each HRV index. Skewness is a measure of symmetry of distribution. Negative or positive skewness is indicated when the left or right tail of the research data fitted to a histogram is longer, respectively. The skewness of a normal distribution is zero. Kurtosis is a measure of whether the distribution curve is peaked (positive) or flat (negative) relative to the normal distribution. The kurtosis of a normally distributed data set is zero. Statistical analysis was performed using IBM SPSS statistics ver. 21 (IBM, New York, US).

\section{Results and Discussion}

3.1. Individual Variations in Autonomic Responses to a Forest Environment. The descriptive statistics of the distribution of the HRV indices are summarized in Table 2. The mean $\ln \mathrm{HF}$ in urban and forest environments was 5.54 and 6.02 $[\ln (\mathrm{ms} 2)]$, respectively. A larger $\ln \mathrm{HF}$ value was observed in forest environments, suggesting activation of the parasympathetic function. The histograms for lnHF are shown in Figure 1. Although the mean values were different, the distribution curves were almost identical between urban and forest environments. In both environments, the distributions indicated slightly left skewed and peaked curves compared with the normal distribution (Figures 1(a) and 1(b)). Differences in $\ln \mathrm{HF}$ between urban and forest environments were calculated individually and depicted as a histogram (Figure 1(c)). Negative values in the difference imply that lnHF was larger in forest than in urban environments, whereas the positive values in the difference imply that lnHF was smaller in forest than in urban environments. A histogram showing the difference indicated a slightly leftskewed and markedly peaked distribution. In the results of the current study, 495 out of 625 (79.2\%) subjects exhibited an increase in $\ln \mathrm{HF}$ in forest environments.

The results of $\ln (\mathrm{LF} / \mathrm{HF})$ were analyzed in a similar way to $\ln \mathrm{HF}$. The mean $\ln (\mathrm{LF} / \mathrm{HF})$ in urban and forest environments was 1.48 and 1.32, respectively. Lower $\ln (\mathrm{LF} / \mathrm{HF})$ values were observed in forest environments, suggesting suppression of the sympathetic function. The histograms for $\ln (\mathrm{LF} / \mathrm{HF})$ are shown in Figure 2. A histogram for the difference in $\ln (\mathrm{LF} / \mathrm{HF})$ between urban and forest environments indicated an almost symmetrical distribution (Figures 2(a) and 2(b)). Furthermore, 397 out of $625(63.5 \%)$ subjects exhibited a decrease in $\ln (\mathrm{LF} / \mathrm{HF})$ in forest environments (Figure $2(\mathrm{c})$ ).

In summary, approximately $80 \%$ of the subjects showed an increase in the parasympathetic activity in forest environments, whereas the remaining subjects exhibited a negative effect of the forest environments. The mean lnHF in urban and forest environments was 5.54 and $6.02[\ln (\mathrm{ms} 2)]$, respectively; thus, the change was approximately $9 \%$. Although the difference in the mean values was statistically significant, the difference appeared marginal. On the other hand, the ratio of positive and negative responders $(80: 20)$ was a more conclusive result as compared with the changes in the mean values. Similar results were obtained for the sympathetic indicator $[\ln (\mathrm{LF} / \mathrm{HF})]$. Thus, histograms are considered to be an efficient tool for the analysis of physiological responses to natural environments in which larger individual variation exists.

3.2. Effect of Respiration and Air Pollution. It has been known that HRV is closely related with respiratory rate. Slower respiratory rate produces larger HF power in the HRV spectrum. Increased HF in a forest environment may relate with slower and/or deeper respiration. Gladwell et al. [28] studied the effects of natural and urban landscapes on heart rate, blood pressure, and respiration. In their results, no significant changes were observed in the respiratory rate and depth, although a parasympathetic indicator of HRV increased in natural landscape similar to the present results. Thus, the change in the respiratory rate is not considered to be a major cause of the increased HF in forest. 


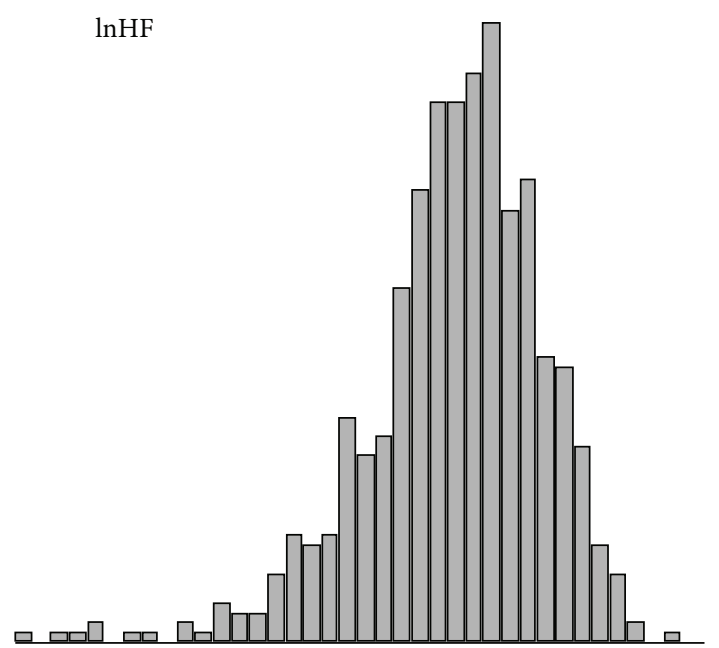

(a) Urban environment

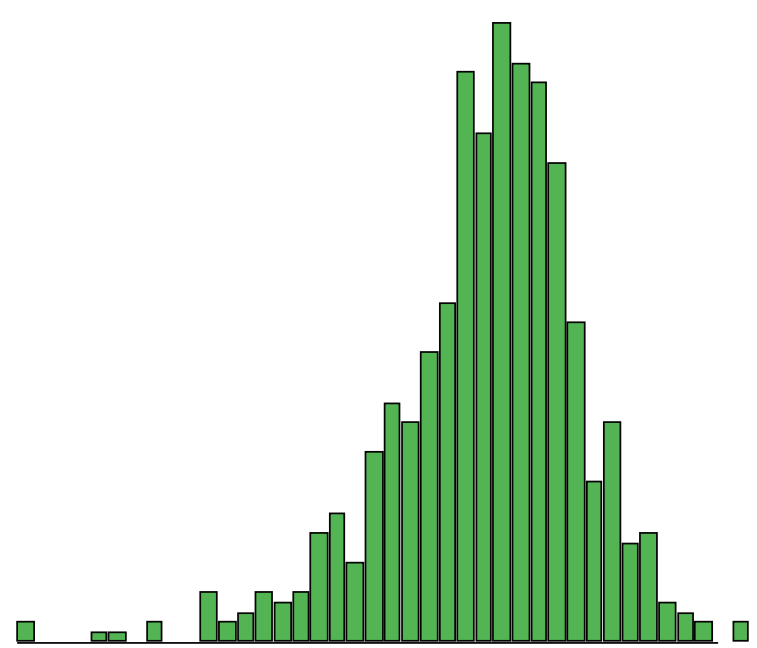

(b) Forest environment

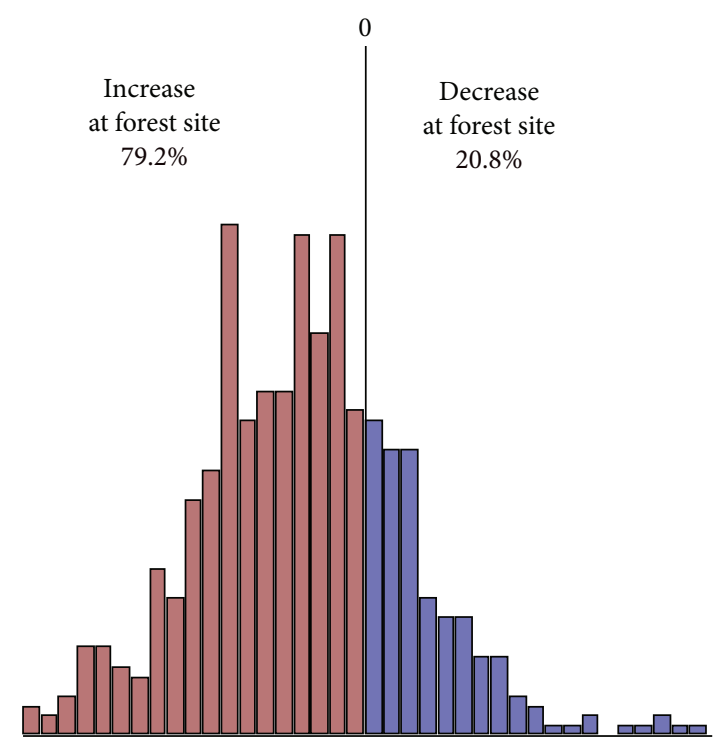

(c) Difference (urban-forest)

FIGURE 1: Histograms showing the high frequency component (lnHF) of heart rate variability in urban and forest environments. (a) lnHF at urban sites, (b) lnHF at forest sites, and (c) difference in lnHF between urban and forest sites.

In recent years, the effect of air pollution on human HRV has been attracting attention in the field of environmental medicine. A relationship between increased PM2.5 (particulate matter with an aerodynamic diameter of $<2.5 \mu \mathrm{m}$ ) and decreased parasympathetic indicator of HRV has been reported $[29,30]$. Because the effect of PM2.5 was considered to be acute rather than chronic [31], the difference in air pollution between urban and forest environments may be an explanation of the present results.

3.3. Biophilia and Biophobia. The biophilia hypothesis was proposed by the distinguished biologist Wilson [32]. Biophilia is defined as the "innate tendency to focus on life and life-like processes" [33]. This tendency could be explained from an evolutionary perspective. For millions of years, human beings (or their recent ancestors) lived in the savannas of Africa. Within this environment, natural features such as trees or forests could provide food, water, or shelter, thereby increasing the probability of survival. Thus, biophilia can be regarded as an adaptive characteristic of human evolution.

On the other hand, it has been known that certain people show a strong dislike for natural settings. This tendency is called biophobia [34]. Biophobia includes certain specific phobias, such as arachnophobia (irrational fear of spiders) or entomophobia (fear of insects). Previous studies have reported that patients displaying arachnophobia showed 


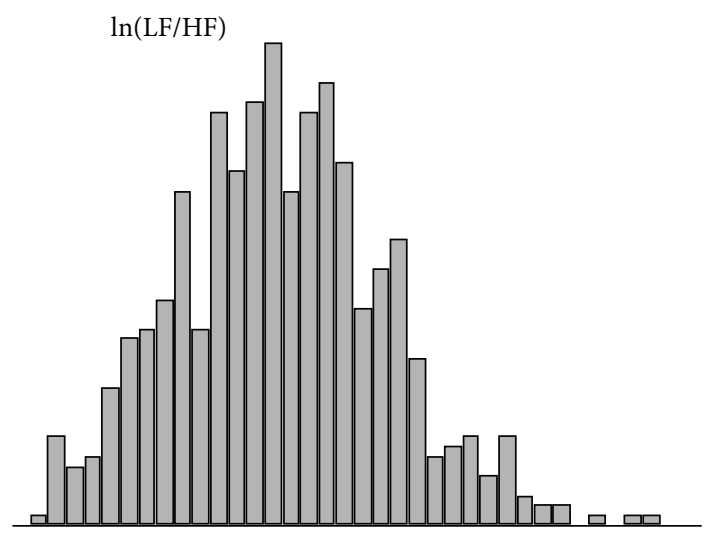

(a) Urban environment

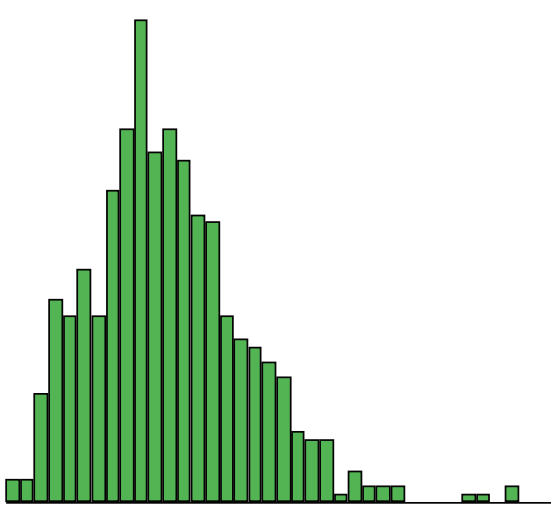

(b) Forest environment

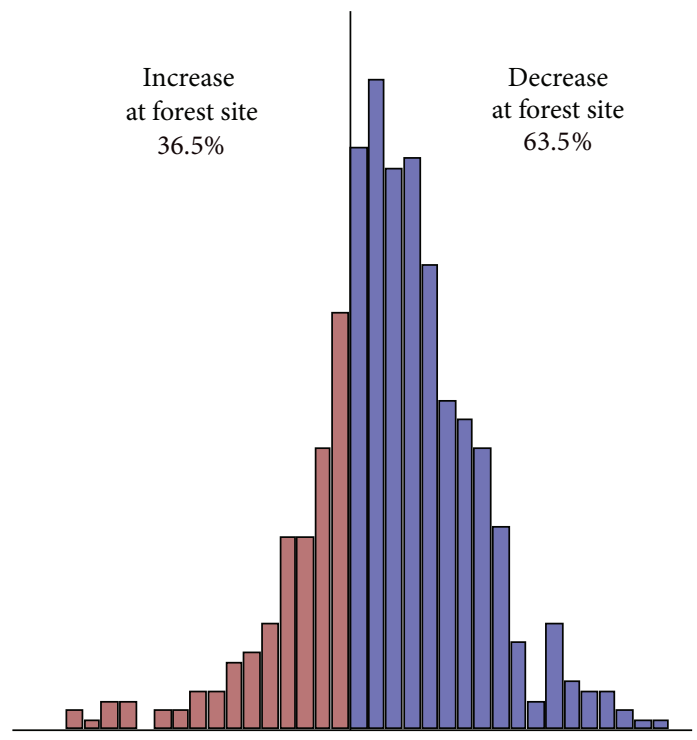

(c) Difference (urban-forest)

FIGURE 2: Histograms showing the low frequency/high frequency ratio $(\ln [\mathrm{LF} / \mathrm{HF}])$ of heart rate variability in urban and forest environments. (a) $\ln (\mathrm{LF} / \mathrm{HF})$ at urban sites, (b) $\ln (\mathrm{LF} / \mathrm{HF})$ at forest sites, and (c) difference in $\ln (\mathrm{LF} / \mathrm{HF})$ between urban and forest sites.

increased HR or HRV during presentation of images of spiders $[35,36]$. Without actually perceiving spiders or insects, people exhibiting these phobias manifested phobic reactions even if they merely imagined spiders or insects in their immediate environment. Therefore, the negative responders in the results of the current study could be explained by these specific phobias to living things. Further consideration of the relationship between physiological responses to the forest environment and biophobia is expected in future studies.

\section{Conclusion}

Autonomic responses to a forest environment were studied in 625 young male subjects. The results were demonstrated using histograms and were analyzed with special reference to individual variations. An increase in the parasympathetic indicator of HRV (lnHF) was observed in approximately $80 \%$ of the subjects. Analysis of the distribution of HRV indices (lnHF and $\ln [\mathrm{LF} / \mathrm{HF}]$ ) demonstrated the effect of forest environments on autonomic activity more specifically than the conventional analysis based on mean values.

\section{Conflict of Interests}

The authors declare that there is no conflict of interests regarding the publication of this paper.

\section{Acknowledgments}

The authors thank Dr. Yuko Tsunetsugu, Mr. Takeshi Morikawa of Forestry and Forest Products Research Institute, Dr. Bum-Jin Park of Chungnam National University, and Dr. Juyoung Lee of Korea Forest Service for their assistance in the experiments. This study was supported by the 2015 Strategic Innovation Promotion (SIP) Program of the National Agriculture and Food Research Organization (NARO) in Japan. 


\section{References}

[1] A. C. Logan, "Dysbiotic drift: mental health, environmental grey space, and microbiota," Journal of Physiological Anthropology, vol. 34, no. 1, article 23, 2015.

[2] R. S. Ulrich, R. F. Simons, B. D. Losito, E. Fiorito, M. A. Miles, and M. Zelson, "Stress recovery during exposure to natural and urban environments," Journal of Environmental Psychology, vol. 11, no. 3, pp. 201-230, 1991.

[3] D. E. Bowler, L. M. Buyung-Ali, T. M. Knight, and A. S. Pullin, "A systematic review of evidence for the added benefits to health of exposure to natural environments," BMC Public Health, vol. 10, no. 1, article 456, 2010.

[4] W. S. Shin, C. S. Shin, and P. S. Yeoun, "The influence of forest therapy camp on depression in alcoholics," Environmental Health and Preventive Medicine, vol. 17, no. 1, pp. 73-76, 2012.

[5] J. Sung, J.-M. Woo, W. Kim, S.-K. Lim, and E.-J. Chung, "The effect of cognitive behavior therapy-based 'forest therapy' program on blood pressure, salivary cortisol level, and quality of life in elderly hypertensive patients," Clinical and Experimental Hypertension, vol. 34, no. 1, pp. 1-7, 2012.

[6] B.-J. Park, Y. Tsunetsugu, T. Kasetani et al., "Physiological effects of Shinrin-yoku (taking in the atmosphere of the forest) - using salivary cortisol and cerebral activity as indicators," Journal of Physiological Anthropology, vol. 26, no. 2, pp. 123-128, 2007.

[7] Q. Li, K. Morimoto, M. Kobayashi et al., "A forest bathing trip increases human natural killer activity and expression of anti-cancer proteins in female subjects," Journal of Biological Regulators \& Homeostatic Agents, vol. 22, no. 1, pp. 45-55, 2008.

[8] Q. Li, M. Kobayashi, Y. Wakayama et al., "Effect of phytoncide from trees on human natural killer function," International Journal of Immunopathology and Pharmacology, vol. 22, no. 4, pp. 951-959, 2009.

[9] Q. Li, "Effect of forest bathing trips on human immune function," Environmental Health and Preventive Medicine, vol. 15, no. 1, pp. 9-17, 2010.

[10] Y. Ohtsuka, N. Yabunaka, and S. Takayama, "Shinrin-yoku (forest-air bathing and walking) effectively decreases blood glucose levels in diabetic patients," International Journal of Biometeorology, vol. 41, no. 3, pp. 125-127, 1998.

[11] S. Akselrod, D. Gordon, F. A. Ubel, D. C. Shannon, A. C. Berger, and R. J. Cohen, "Power spectrum analysis of heart rate fluctuation: a quantitative probe of beat-to-beat cardiovascular control," Science, vol. 213, no. 4504, pp. 220-222, 1981.

[12] A. Malliani, M. Pagani, F. Lombardi, and S. Cerutti, "Cardiovascular neural regulation explored in the frequency domain," Circulation, vol. 84, no. 2, pp. 482-492, 1991.

[13] N. Montano, T. G. Ruscone, A. Porta, F. Lombardi, M. Pagani, and A. Malliani, "Power spectrum analysis of heart rate variability to assess the changes in sympathovagal balance during graded orthostatic tilt," Circulation, vol. 90, no. 4 I, pp. 18261831, 1994.

[14] S. H. Hyun, J. W. Im, W. S. Jung et al., "Effect of ST36 acupuncture on hyperventilation-induced $\mathrm{CO}_{2}$ reactivity of the basilar and middle cerebral arteries and heart rate variability in normal subjects," Evidence-Based Complementary and Alternative Medicine, vol. 2014, Article ID 574986, 7 pages, 2014.

[15] W. Guangjun, T. Yuying, J. Shuyong, Z. Wenting, and Z. Weibo, "Bilateral Hegu acupoints have the same effect on the heart rate variability of the healthy subjects," Evidence-Based Complementary and Alternative Medicine, vol. 2014, Article ID 106940, 5 pages, 2014.
[16] Y. Tsunetsugu, B.-J. Park, H. Ishii, H. Hirano, T. Kagawa, and Y. Miyazaki, "Physiological effects of Shinrin-yoku (taking in the atmosphere of the forest) in an old-growth broadleaf forest in Yamagata Prefecture, Japan," Journal of Physiological Anthropology, vol. 26, no. 2, pp. 135-142, 2007.

[17] B.-J. Park, Y. Tsunetsugu, H. Ishii et al., "Physiological effects of Shinrin-yoku (taking in the atmosphere of the forest) in a mixed forest in Shinano Town, Japan," Scandinavian Journal of Forest Research, vol. 23, no. 3, pp. 278-283, 2008.

[18] B.-J. Park, Y. Tsunetsugu, T. Kasetani, T. Morikawa, T. Kagawa, and Y. Miyazaki, "Physiological effects of forest recreation in a young conifer forest in Hinokage Town, Japan," Silva Fennica, vol. 43, no. 2, pp. 291-301, 2009.

[19] B. J. Park, Y. Tsunetsugu, T. Kasetani, T. Kagawa, and Y. Miyazaki, "The physiological effects of Shinrin-yoku (taking in the forest atmosphere or forest bathing): evidence from field experiments in 24 forests across Japan," Environmental Health and Preventive Medicine, vol. 15, no. 1, pp. 18-26, 2010.

[20] C. Song, D. Joung, H. Ikei et al., "Physiological and psychological effects of walking on young males in urban parks in winter," Journal of Physiological Anthropology, vol. 32, no. 1, article 18, 2013.

[21] C. Song, H. Ikei, M. Igarashi, M. Miwa, M. Takagaki, and Y. Miyazaki, "Physiological and psychological responses of young males during spring-time walks in urban parks," Journal of Physiological Anthropology, vol. 33, article 8, 2014.

[22] H. Ikei, C. Song, M. Igarashi, T. Namekawa, and Y. Miyazaki, "Physiological and psychological relaxing effects of visual stimulation with foliage plants in high school students," Advances in Horticultural Science, vol. 28, no. 2, pp. 111-116, 2014.

[23] M. Igarashi, M. Aga, H. Ikei, T. Namekawa, and Y. Miyazaki, "Physiological and psychological effects on high school students of viewing real and artificial pansies," International Journal of Environmental Research and Public Health, vol. 12, no. 3, pp. 2521-2531, 2015.

[24] Task Force of the European Society of Cardiology and the North American Society of Pacing and Electrophysiology, "Heart rate variability-standards of measurement, physiological interpretation, and clinical use," Circulation, vol. 93, no. 5, pp. 1043-1065, 1996.

[25] A. F. Bennett, "Interindividual variability: an under-utilized resource," in New Directions in Ecological Physiology, M. E. Feder, A. F. Bennett, W. W. Burggren, and R. B. Huey, Eds., pp. 147-169, Cambridge University Press, Cambridge, UK, 1987.

[26] H. Kobayashi, B.-J. Park, and Y. Miyazaki, "Normative references of heart rate variability and salivary alpha-amylase in a healthy young male population," Journal of Physiological Anthropology, vol. 31, no. 1, article 9, 2012.

[27] H. Kobayashi, "Does paced breathing improve the reproducibility of heart rate variability measurements?" Journal of Physiological Anthropology, vol. 28, no. 5, pp. 225-230, 2009.

[28] V. F. Gladwell, D. K. Brown, J. L. Barton et al., "The effects of views of nature on autonomic control," European Journal of Applied Physiology, vol. 112, no. 9, pp. 3379-3386, 2012.

[29] D. R. Gold, A. Litonjua, J. Schwartz et al., "Ambient pollution and heart rate variability," Circulation, vol. 101, no. 11, pp. 12671273, 2000.

[30] C. A. Pope III, M. L. Hansen, R. W. Long et al., "Ambient particulate air pollution, heart rate variability, and blood markers of inflammation in a panel of elderly subjects," Environmental Health Perspectives, vol. 112, no. 3, pp. 339-345, 2004. 
[31] Z. T. Fan, Q. Meng, C. Weisel et al., "Acute exposure to elevated $\mathrm{PM}_{2.5}$ generated by traffic and cardiopulmonary health effects in healthy older adults," Journal of Exposure Science and Environmental Epidemiology, vol. 19, no. 5, pp. 525-533, 2009.

[32] E. O. Wilson, Biophilia: The Human Bond with Other Species, Harvard University Press, Cambridge, UK, 1984.

[33] E. Gullone, "The biophilia hypothesis and life in the 21st century: increasing mental health or increasing pathology?" Journal of Happiness Studies, vol. 1, no. 3, pp. 293-322, 2000.

[34] R. S. Ulrich, "Biophilia, biophobia, and natural landscapes," in The Biophilia Hypothesis, S. R. Kellert and E. O. Wilson, Eds., pp. 73-137, Island Press, Washington, DC, USA, 1993.

[35] M. Sarlo, D. Palomba, A. Angrilli, and L. Stegagno, "Blood phobia and spider phobia: two specific phobias with different autonomic cardiac modulations," Biological Psychology, vol. 60, no. 2-3, pp. 91-108, 2002.

[36] G. P. Prigatano and H. J. Johnson, "Autonomic nervous system changes associated with a spider phobic reaction," Journal of Abnormal Psychology, vol. 83, no. 2, pp. 169-177, 1974. 


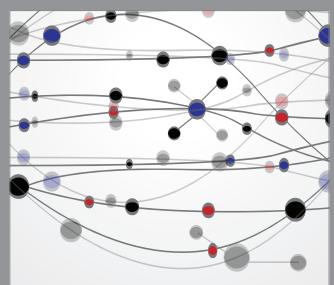

The Scientific World Journal
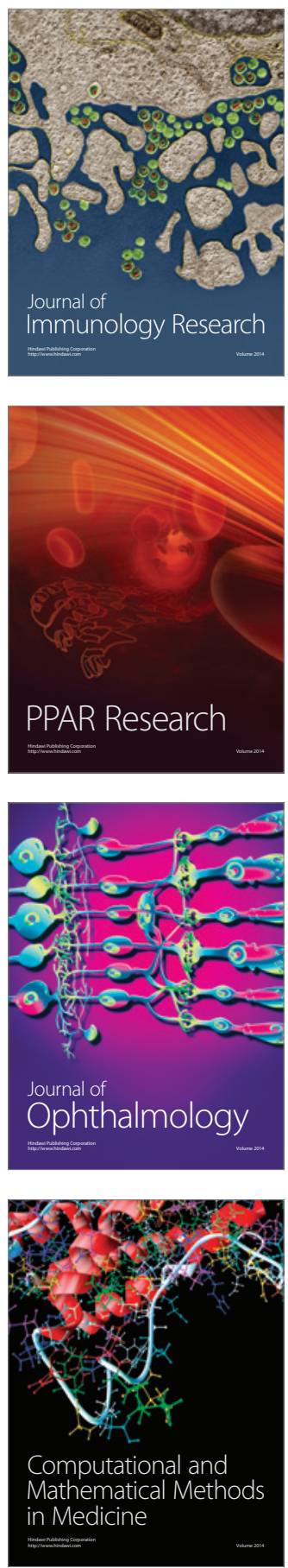

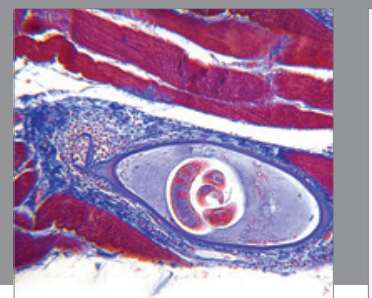

Gastroenterology

Research and Practice
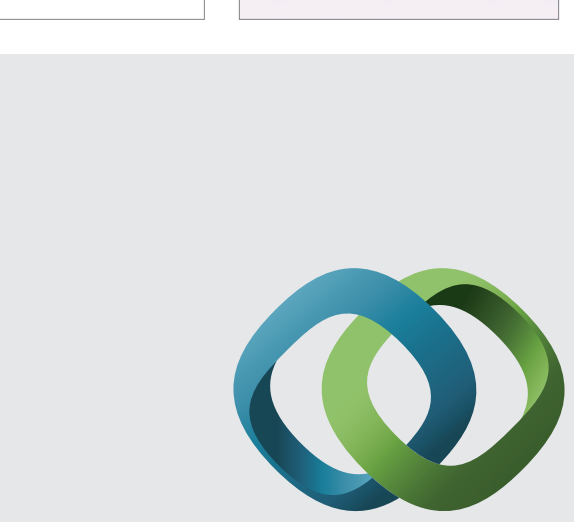

\section{Hindawi}

Submit your manuscripts at

http://www.hindawi.com
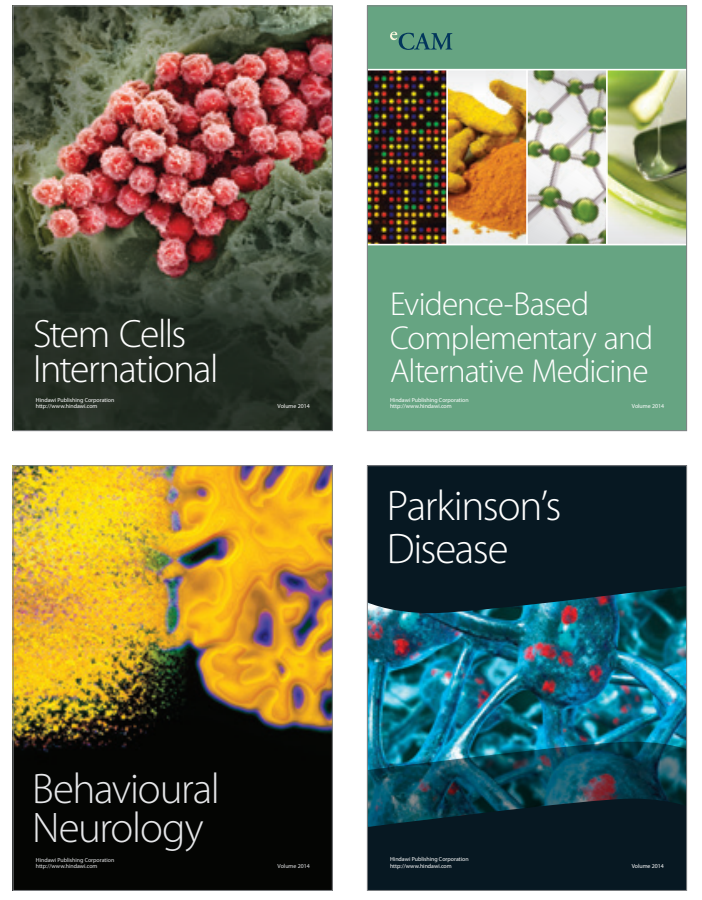
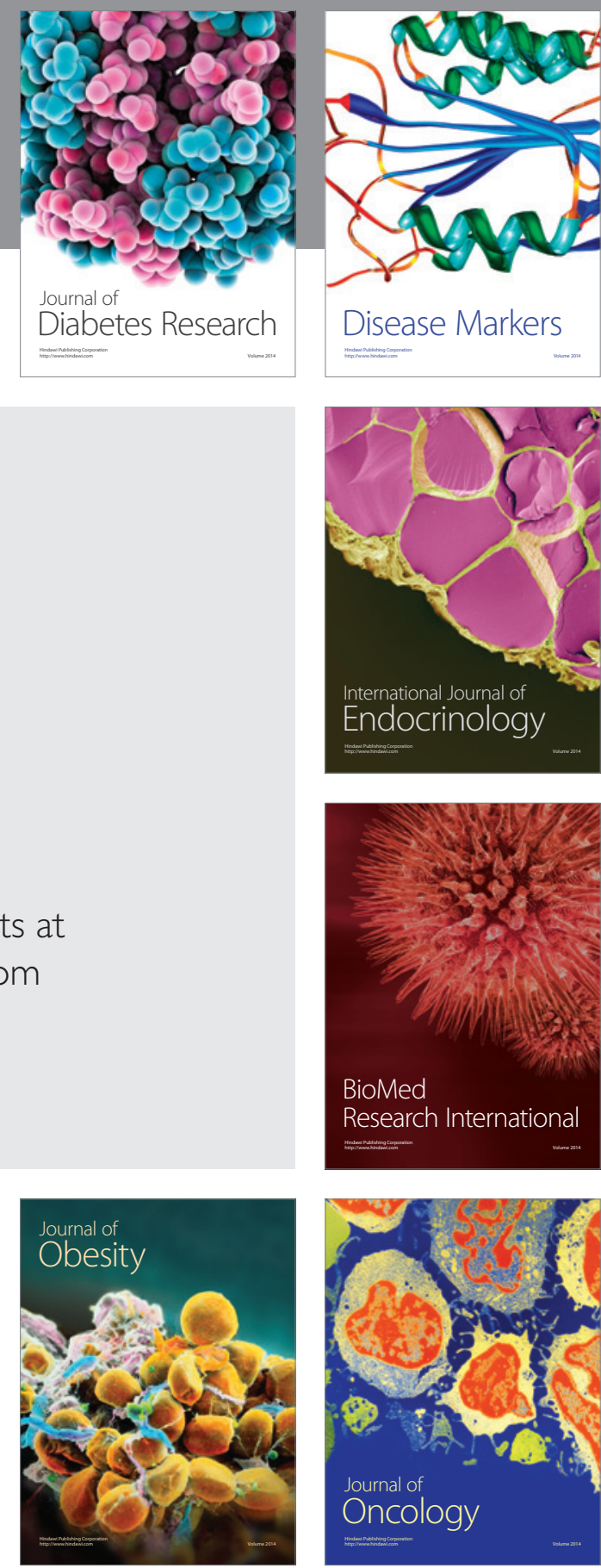

Disease Markers
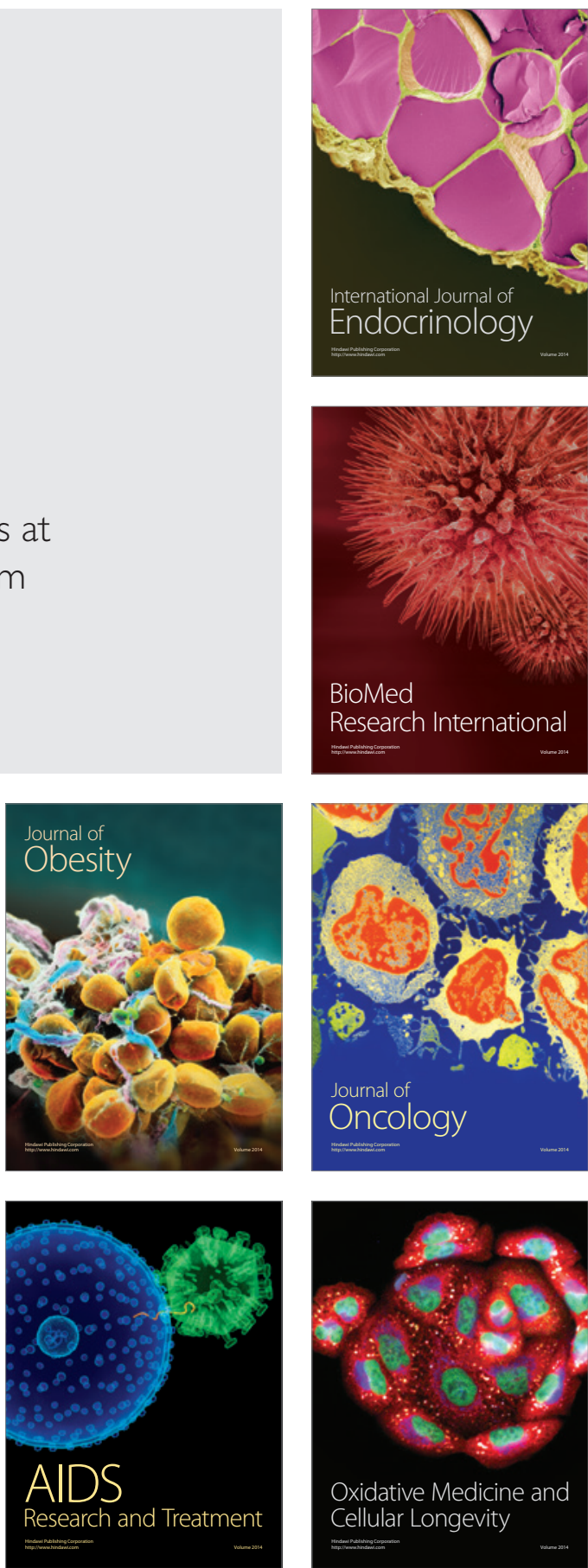